\title{
Cyclic Cold Stresses before Transplanting Influence Tomato Seedling Growth, but Not Fruit Earliness, Fresh-market Yield, or Quality
}

\author{
Robert J. Dufault ${ }^{1}$ and Regina R. Melton ${ }^{2}$ \\ Clemson University, Coastal Research and Education Center, 2865 Savannah Highway, \\ Charleston, SC 29414 \\ Additional index words. Lycopersicon esculentum, solanaceae
}

\begin{abstract}
Tomato seedlings (Lycopersicon esculentum Mill. 'Sunny') were exposed to cyclic cold stress at $2 \pm 1 C$, then to $29 \pm 6 \mathrm{C}$ in a greenhouse before being transplanted to the field. Cold-stressed seedlings were transplanted when the risk of ambient cold stress was negligible. In the first year of a 2-year study, transplants were exposed to 2C for 3, 6, or 12 hours for 1, 3, or 6 days before field planting. In the second year, transplants were exposed to 2C for 6,12 , or 18 hours for 4, 7, or 10 days before field planting. In the first year, cold stress generally stimulated increases in seedling height, leaf area, and shoot and root dry weights but decreased chlorophyll content. In the second year, all seedling growth characteristics except leaf area and plant height were diminished in response to longer cold-stress treatment. In both years, earliness, total productivity, and quality were unaffected by any stress treatment. Therefore, cold stress occurring before transplanting has a negligible effect on earliness, yield, or quality.
\end{abstract}

Tomatoes are established in coastal South Carolina in the field by transplanting. The major benefit of transplant use is earlier production. However, stresses during the stand-establishment phase may delay plant development and may negate any benefit to earliness. Normally, many successive hand-harvests are required for acceptable yields. Because of high labor costs, methods to reduce harvest costs are desired. It is imperative, therefore, that transplanted tomatoes become established rapidly and uniformly to ensure maximum yield with few harvests.

To time the production to maximize returns, tomatoes in coastal South Carolina are transplanted near the last killing frosts. In some cases, late-season frosts may kill newly planted fields, or periods of cold weather may stagnate growth and establishment. It is not known whether cold stress occurring during the seedling phase retards growth and development over the course of the season. Previous studies with cotton (Christiansen and Thomas, 1969), carrots and lettuce (Currah, 1978), red beets (Hegarty and Thompson, 1974), and onions (Henriksen, 1978) have confirmed that stress incurred early in crop development reduced yield. Little research has been done on the long-term effects of short-term stresses on transplanted vegetable crops.

Customary methods of reducing stress in the field may involve proper acclimation of transplants by withholding water or exposing the transplants in holding areas to low (Wheaton and Morris, 1968) or high temperature extremes. However, these techniques may inhibit tomato growth and development. The earliness of hardened tomato transplants in cold frames can be reduced in contrast to nonhardened plants (Brasher and Westover, 1937; Porter, 1936). Brasher (1941) stated that any method used to harden young tomato plants slows their field performance permanently, probably decreasing the yield in proportion to the severity of the hardening treatment. However, gradual exposure of tomato seedlings to low temperatures can increase the ability of seedlings to tolerate further cold stresses (Shen

Received for publication 21 Aug. 1989. Technical contribution no. 3038 of the South Carolina Agricultural Experiment Station, Clemson Univ. The cost of publishing this paper was defrayed in part by the payment of page charges. Under postal regulations, this paper therefore must be hereby marked advertisement solely to indicate this fact.

'Associate Professor.

${ }^{2}$ Graduate Assistant. and $\mathrm{Li}, 1983$ ). Wheaton and Morris (1968) reported that a conditioning period of $3 \mathrm{hr}$ at $12.5 \mathrm{C}$ was sufficient to give some protection, and maximum protection was achieved in $48 \mathrm{hr}$. These studies contradict earlier work (Brasher and Westover, 1937; Brasher, 1941; Porter, 1936) that reported earliness and yield reductions with cold-hardened transplants.

Low-temperature treatment during the seedling stage may have beneficial effects on flowering. Low night temperatures in the 10 to $13 \mathrm{C}$ range imposed on seedlings promoted earlier floral initiation and more flowers (Wittier and Teubner, 1957) and higher early and total yields than higher temperatures (Wittier and Teubner, 1956). More work is needed to clarify the practical consequences of short-term temperature stresses occurring near the time of transplanting on long-term performance. The objectives of this study were to determine the effects of short-term cold-stress duration and frequency occurring before field planting on tomato seedling growth, transplant shock, earliness, yield, and quality.

\section{Materials and Methods}

Cold stress vs. transplant growth. 'Sunny' tomato seeds were planted in Speedling cell trays (size 150-3.8 $\times 3.8 \times 6.4$ $\mathrm{cm}$ ) filled with a synthetic soil medium (Terralite Redi-Earth, W.R. Grace, Cambridge, Mass.) on 12 Mar. 1987 and on 11 Mar. 1988. The transplants were fertilized with solutions containing 20N-9P-18K at $150 \mathrm{mg} \cdot \mathrm{liter}^{-1}$ on 2 and 6 Apr. 1987 and 28 Mar. and 1 Apr. 1988, and 9N-21P-13K at $50 \mathrm{mg} \cdot$ liter $^{-1}$ on 9 and 13 Apr. 1987 and 30 Mar. and 6 Apr. 1988 for the two tests, respectively. The greenhouse during the growth periods was at $29 \pm 6 \mathrm{C}$.

The cold-stress treatments consisted of factorial combinations of stress duration and frequency. In the first year, seedlings were exposed to $2 \mathrm{C}$ for 3,6 , or $12 \mathrm{hr}$ (duration) for 1,3 , or 6 days (frequency) before field planting. In the second year, seedlings were exposed to $2 \mathrm{C}$ for 6,12 , or $18 \mathrm{hr}$ for 4,7 , or 10 days before field planting. A non-stressed control was included each year. A $3 \times 3$ factorial combination of cold-stress duration and frequency treatments produced nine unique cold-stress regimes plus a nonstressed control. Speedling cell trays were cut into quarters and each quarter, representing one replication, contained six plants for transplant growth analysis and 10 plants 
for field planting. The experimental treatments were replicated four times, and the trays arranged in a randomized completeblock design in the greenhouse. Cold stress was accomplished by repeatedly moving the trays into an empty walk-in cooler ( 2 \pm 1C), using a schedule described in Table 1, and then.back into a greenhouse $(29 \pm 6 \mathrm{C})$ after the prescribed time. All coldstress treatments were planned to terminate at the same time for uniform transplant data collection and subsequent field planting.

The greenhouse growth period and cold-stress treatments were terminated 41 and 38 days after seeding in 1987 and 1988, respectively. The following growth variables were quantified: leaf area/seedling (including petioles) with a leaf area meter (Model LI-3000, LI-COR, Lincoln, Neb.); stem diameter (measured at cotyledon attachment); seedling height (measured from the medium surface to the approximate apical meristem tip); number of expanded true leaves (considered expanded if petiole easily visible); shoot and washed-root dry weights (dried at 65C for $24 \mathrm{hr})$. Leaf disks $\left(0.31 \mathrm{~cm}^{2}\right)$ were removed from the second true leaf above the cotyledons and composite from five randomly selected plants per treatment and total chlorophyll was determined (Moran, 1982). Growth data were tested by analysis of variance (ANOVA) and mean separation performed using least significant difference. Orthogonal contrasts were performed comparing the effect of cold stress (pooled over all stress treatments) to the non-cold-stressed control. The relative importance of cold-stress duration and frequency was determined by partitioning the total sum of squares for treatments into main and interaction effects and expressing these individual contributions to variation as a percentage of the sum of squares for the model (composed of only those sources of variation in the ANOVA).

Cold stress vs. transplant shock, earliness, yield, and quality. The seedlings from the 10 temperature treatments were planted on 22 Apr. 1987 and 18 Apr. 1988 after all risk of ambient cold stress had passed at the Clemson Univ. Coastal Research and Education Center in Charleston, S.C. The soil type was a Yauhannah loamy fine sand, an aquic hapudults ( $\mathrm{pH}$ 7.2). Before planting in 1987, the field was fertilized with $77 \mathrm{~N}-55 \mathrm{P}-100 \mathrm{~K}-$ $39 \mathrm{Ca} \mathrm{kg} \cdot \mathrm{ha}^{-1}$; in 1988 , the field was treated with $181 \mathrm{~N}-69 \mathrm{P}-$ $175 \mathrm{~K}-36 \mathrm{Ca} \mathrm{kg}$ fertilizer/ha and $355 \mathrm{~kg}$ dolomitic lime/ha. In both years, the beds were fumigated with methyl bromide and mulched with black plastic mulch. In 1987, overhead irrigation was used; in 1988, drip irrigation tubing was buried on the east shoulder of the beds before mulching. Plants were spaced 46 $\mathrm{cm}$ apart within rows on $1.8-\mathrm{m}$ beds $(\approx 27,000$ plants/ha). A treatment plot consisted of one row, $4.6 \mathrm{~m}$ long, and contained 10 plants. Each treatment plot was replicated four times in a randomized complete-block design. The plots were irrigated when needed as indicated by tensiometers. The plants were staked, tied up with 'strings, and all lateral shoots were removed below the first flower cluster, except the first lateral directly below this cluster.

The long-term effects of cold stress on transplant growth and development in the field were monitored. In this study, transplant shock was defined as the percentage of all leaves on a plant exhibiting serious necrosis, chlorosis, or damage. Transplant shock data were collected on 1 May 1987 and 29 Apr. 1988. The number of days to first flower and to first fruit on the first fruit cluster $(\approx 10-\mathrm{cm}$ diameter) was evaluated weekly.

All fruit showing a slight pink coloration were hand-harvested on 2, 8, 15, and 23 July 1987 or 28 June, 5, 12, 19 July 1988. Fruit was graded into diameter categories as large $(>70 \mathrm{~mm})$, medium (55 to $69 \mathrm{~mm}$ ), and small $(<55 \mathrm{~mm})$. Cull fruit was graded according to quality defects, such as blossom-end rot, corky blossom end (callus $>5 \mathrm{~mm}$ in diameter), catface, seams, and rough fruit.

Statistical analysis of the field data was performed as described above.

Table 1. Schedule of $2 \mathrm{C}$ cold-stress treatments imposed on 'Sunny' tomato seedlings before field planting in 1987 and 1988.

\begin{tabular}{|c|c|c|c|c|c|c|c|c|}
\hline \multirow{3}{*}{$\begin{array}{l}\text { Stress } \\
\text { duration } \\
(\mathrm{hr})\end{array}$} & \multirow{2}{*}{$\begin{array}{l}\text { Cold-stress } \\
\text { frequency }\end{array}$} & \multicolumn{7}{|c|}{ Clock hours } \\
\hline & & \multicolumn{7}{|c|}{ Days before planting in the field ${ }^{2}$} \\
\hline & (No. of & days) & 6 & 5 & 4 & 3 & 2 & 1 \\
\hline & & \multicolumn{7}{|c|}{1987} \\
\hline 3 & 1 & & G & G & G & G & G & $1600-1900$ \\
\hline 3 & 3 & & $\mathrm{G}$ & G & G & $1600-1900$ & $1600-1900$ & $1600-1900$ \\
\hline 3 & 6 & & $600-1900$ & $1600-1900$ & $1600-1900$ & $1600-1900$ & $1600-1900$ & $1600-1900$ \\
\hline 6 & 1 & & $\mathrm{G}$ & $\mathrm{G}$ & G & G & G & $1600-2200$ \\
\hline 6 & 3 & & $\mathrm{G}$ & $\mathrm{G}$ & G & $1600-2200$ & $1600-2200$ & $1600-2200$ \\
\hline 6 & 6 & & $600-2200$ & $1600-2200$ & $1600-2200$ & $1600-2200$ & $1600-2200$ & $1600-2200$ \\
\hline 12 & 1 & & $\mathrm{G}$ & G & $\mathrm{G}$ & $\mathrm{G}$ & $\mathrm{G}$ & $1930-0730$ \\
\hline 12 & 3 & & G & G & G & $1930-0730$ & $1930-0730$ & $1930-0730$ \\
\hline 12 & 6 & & $930-0730$ & $1930-0730$ & $1930-0730$ & $1930-0730$ & $1930-0730$ & $1930-0730$ \\
\hline
\end{tabular}

\begin{tabular}{|c|c|c|c|c|c|c|c|}
\hline & & \multicolumn{6}{|c|}{1988} \\
\hline & & 10 & 9 & 8 & 7 & 6 & $5-1^{y}$ \\
\hline 6 & 4 & G & G & G & G & G & $1400-2000$ \\
\hline 6 & 7 & $\mathrm{G}$ & G & $\mathrm{G}$ & $1400-2000$ & $1400-2000$ & $1400-2000$ \\
\hline 6 & 10 & $1400-2000$ & $1400-2000$ & $1400-2000$ & $1400-2000$ & $1400-2000$ & $1400-2000$ \\
\hline 12 & 4 & $\mathrm{G}$ & $\mathrm{G}$ & $\mathrm{G}$ & G & $\mathrm{G}$ & $2000-0800$ \\
\hline 12 & 7 & $\mathrm{G}$ & $\mathrm{G}$ & $\mathrm{G}$ & $2000-0800$ & $2000-0800$ & $2000-0800$ \\
\hline 12 & 10 & $2000-0800$ & $2000-0800$ & $2000-0800$ & $2000-0800$ & $2000-0800$ & $2000-0800$ \\
\hline 18 & 4 & $\mathrm{G}$ & $\mathrm{G}$ & $\mathrm{G}$ & $\mathrm{G}$ & $\mathrm{G}$ & $1400-0800$ \\
\hline 18 & 7 & $\mathrm{G}$ & $\mathrm{G}$ & $\mathrm{G}$ & $1400-0800$ & $1400-0800$ & $1400-0800$ \\
\hline 18 & 10 & $1400-0800$ & $1400-0800$ & $1400-0800$ & $1400-0800$ & $1400-0800$ & $1400-0800$ \\
\hline
\end{tabular}

${ }^{2} \mathrm{G}=$ Seedlings placed in greenhouse for $24 \mathrm{hr}$.

${ }^{y}$ Seedlings repeatedly exposed to cold stress for the last 5 days before field planting. 


\section{Results}

Cold stress vs. seedling growth. Seedling response to coldstress duration and frequency differed between the first (1987) and second (1988) experiments. In the first experiment, the main effect of cold-stress duration did not affect any growth variables (Table 2). Similarly, cold-stress frequency did not affect any growth variables except total chlorophyll content. As cold-stress frequency increased progressively from 1 to 6 days, the chlorophyll content decreased. The major sources of variation in plant height, leaf area, stem diameter, and shoot and root dry weights were attributable to the interaction between duration and frequency and to uncontrolled error. The number of leaves produced on seedlings was unaffected by any coldstress frequency, duration, or their interaction; unexplained error was the major source of variation in leaf number. Generally, even though plant growth varied differentially as cold-stress frequency interacted with duration, tomato seedling growth was similar between the nonstressed control and seedlings exposed to 6 days of 12-hr cold stress (Table 3). Orthogonal contrasts comparing the unstressed control to the pooled mean of all coldstress treatments indicated that cold stress stimulated an increase in plant height, leaf area, and shoot and root dry weights, but a decrease in chlorophyll content (Table 2).

In the second experiment, the levels of cold-stress duration and frequency were increased to determine if seedlings can withstand even greater low temperature extremes. Uncontrolled error tended to account for more of the variation in all these variables than either stress duration or frequency (Table 2). Cold-stress duration accounted for major portions of variation in stem diameter, leaf number, shoot and root dry weights, and total chlorophyll content. Root and shoot dry weights increased as cold- stress duration increased from 6 to $12 \mathrm{hr}$, but as exposure increased to $18 \mathrm{hr}$, root dry weight decreased and shoot dry weight was equivalent to weights after $6 \mathrm{hr}$ of cold-stress duration. Leaf number remained stable for up to $12 \mathrm{hr}$ of cold-stress duration, but leaf number decreased as duration increased to $18 \mathrm{hr}$. However, chlorophyll content decreased as duration increased from 6 to $12 \mathrm{hr}$ with no further decrease at longer durations. Coldstress frequency did not affect plant height, leaf number, shoot dry weight, or chlorophyll content. In contrast, as cold-stress frequency increased, leaf area, stem diameter, and root dry weights decreased. Generally, as frequency increased from 7 to 10 days, these growth variables decreased. Unlike in the first experiment, the interaction between duration and frequency was not significant, except with shoot and root dry weights. However, this variation. was considered minor. Converse to the first experiment, orthogonal contrasts comparing the unstressed control to the pooled mean of all cold-stress treatments in the second year indicated that all seedling growth variables except leaf area were reduced in response to cold stress. The milder cold stress in the first year seemed to be stimulator-y, but the more extreme cold stresses in the second year were deleterious.

Cold stress vs. field performance. Orthogonal contrasts comparing the unstressed control to the pooled mean of all coldstress treatments indicated, as expected, that cold-stressed plants exhibited more transplant shock, as expressed by leaf death, than nonstressed (Table 4). In both experiments, the major source of variation in the incidence of transplant shock was cold-stress duration and, to a lesser extent, cold-stress frequency. In the first experiment, the number of dead or necrotic leaves (counted on seedlings $\approx 11$ days after transplanting) was not affected by cold stress lasting only $6 \mathrm{hr}$. However, increasing the duration

Table 2. Effects of low-temperature stress duration and frequency on tomato seedling growth ${ }^{2}$.

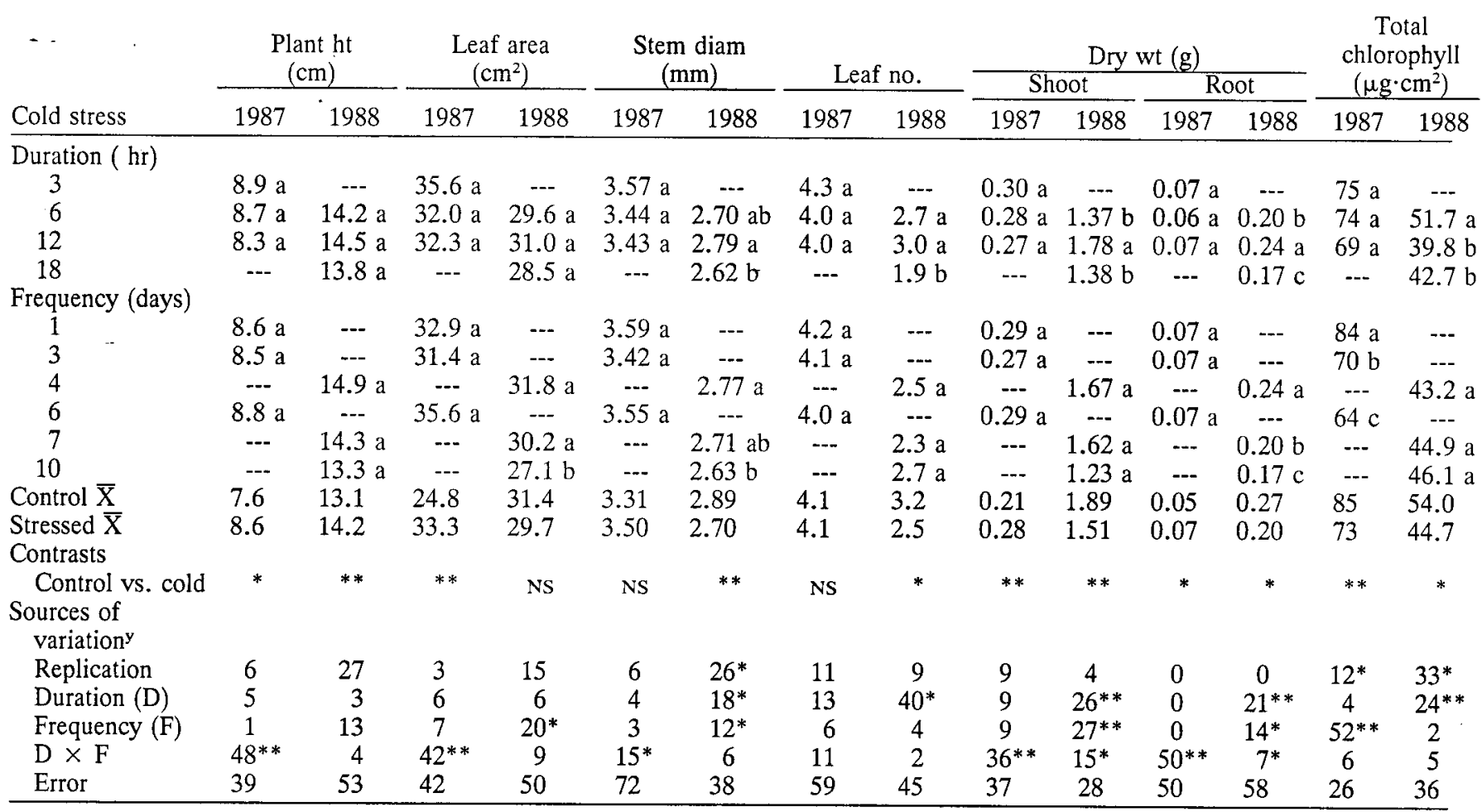

${ }^{z}$ Means within columns and main effects separated by least significant difference at $P=0.05$.

${ }^{y}$ Composed of only those sources of variation given in this ANOVA.

NS, ***Nonsignificant or significant at $P=0.05$ or 0.10 , respectively. 
Table 3. Interaction of low-temperature stress frequency and duration on tomato seedling growth in 1987.

\begin{tabular}{|c|c|c|c|c|}
\hline \multirow{2}{*}{$\begin{array}{l}\text { Duration } \\
\text { (hr) }\end{array}$} & \multicolumn{4}{|c|}{ Frequency (days) $\mathrm{z}$} \\
\hline & 0 & 1 & 3 & 6 \\
\hline \multicolumn{5}{|c|}{ Plant ht $(\mathrm{cm})$} \\
\hline 0 & $8.4 \mathrm{~cd}$ & --- & --- & --- \\
\hline 3 & -.. & $8.5 \mathrm{~cd}$ & $8.1 \mathrm{de}$ & $10.2 \mathrm{a}$ \\
\hline 6 & -- & $9.5 \mathrm{~b}$ & $8.7 \mathrm{c}$ & $7.8 \mathrm{e}$ \\
\hline 12 & --- & $\begin{array}{c}7.8 \mathrm{e} \\
\text { Leaf area }\left(\mathrm{cm}^{2}\right)\end{array}$ & $8.8 \mathrm{c}$ & $8.4 \mathrm{~cd}$ \\
\hline 0 & $35.0 \mathrm{~b}$ & -.- & --- & -- \\
\hline 3 & -.- & $34.0 \quad b$ & $28.3 \mathrm{c}$ & 44.6 a \\
\hline 6 & -- & $36.1 \mathrm{~b}$ & $32.9 \mathrm{~b}$ & $27.2 \mathrm{c}$ \\
\hline 12 & $\cdots$ & $28.6 \mathrm{c}$ & $33.1 \mathrm{~b}$ & $35.0 \mathrm{~b}$ \\
\hline \multicolumn{5}{|c|}{ Stem diam $(\mathrm{mm})$} \\
\hline 3 & $\begin{array}{c}3.52 \mathrm{~cd} \\
\ldots . .\end{array}$ & $3.51 \mathrm{~cd}$ & $3 . \overline{42} \mathrm{c}-\mathrm{f}$ & $3 . \overline{80} \mathrm{a}$ \\
\hline 6 & $\cdots$ & $3.65 \mathrm{~b}$ & 3.39 def & $3.30 \mathrm{f}$ \\
\hline 12 & $\ldots$ & $\begin{array}{c}3.32 \text { ef } \\
\text { Shoot dry wt (g) }\end{array}$ & 3.44 cde & $3.53 \mathrm{bc}$ \\
\hline 0 & $0.29 \mathrm{bc}$ & $\ldots$ & --- & -- \\
\hline 3 & --- & $0.30 \mathrm{~b}$ & $0.25 \mathrm{de}$ & $0.35 \mathrm{a}$ \\
\hline 6 & --- & $0.34 \mathrm{a}$ & $0.27 \mathrm{~cd}$ & $0.23 \mathrm{e}$ \\
\hline 12 & $-\cdots$ & $\begin{array}{c}0.24 \mathrm{e} \\
\text { Root dry wt (g) }\end{array}$ & $0.28 \mathrm{bcd}$ & $0.29 \mathrm{bc}$ \\
\hline 0 & $0.08 \mathrm{a}$ & -.- & -- & $-\cdots$ \\
\hline 3 & --- & $0.08 \mathrm{a}$ & $0.06 \mathrm{~b}$ & $0.08 \mathrm{a}$ \\
\hline 6 & --- & $0.07 \mathrm{a}$ & $0.06 \mathrm{~b}$ & $0.06 \mathrm{~b}$ \\
\hline 12 & --- & $0.05 \mathrm{c}$ & $0.07 \mathrm{a}$ & $0.08 \mathrm{a}$ \\
\hline
\end{tabular}

${ }^{\mathrm{z}}$ Mean separation of each variable within rows and columns by least significant difference at $P=0.05$.

Table 4. Effects of low-temperature stress duration and frequency on leaf viability $\approx 11$ days after field transplanting in 1987 and 1988 .

\begin{tabular}{|c|c|c|c|c|}
\hline \multirow[b]{3}{*}{ Cold stress } & \multicolumn{4}{|c|}{ No. of leaves ${ }^{2}$} \\
\hline & \multicolumn{2}{|c|}{ Live } & \multicolumn{2}{|c|}{ Dead } \\
\hline & $1987^{\circ}$ & 1988 & 1987 & 1988 \\
\hline \multicolumn{5}{|l|}{ Duration (hr) } \\
\hline 3 & $5.1 \mathrm{a}$ & -- & $0.1 \mathrm{~b}$ & $--\cdot$ \\
\hline 6 & $5.1 \mathrm{a}$ & $3.7 \mathrm{a}$ & $0.0 \mathrm{~b}$ & $1.0 \mathrm{c}$ \\
\hline 12 & $4.1 \mathrm{~b}$ & $3.3 \mathrm{~b}$ & $0.9 \mathrm{a}$ & $1.3 \mathrm{~b}$ \\
\hline 18 & -- & $2.6 \mathrm{c}$ & -- & $1.7 \mathrm{a}$ \\
\hline \multicolumn{5}{|l|}{ Frequency (days) } \\
\hline 1 & $5.1 \mathrm{a}$ & --- & $0.1 \mathrm{c}$ & --- \\
\hline 3 & $4.4 \mathrm{c}$ & $\cdots$ & $0.6 \mathrm{a}$ & --- \\
\hline 4 & $\cdots$ & $2.7 \mathrm{c}$ & -- & $1.8 \mathrm{a}$ \\
\hline 6 & $4.8 \mathrm{~b}$ & --- & $0.3 \mathrm{~b}$ & -- \\
\hline 7 & --. & $3.2 \mathrm{~b}$ & --- & $1.3 \mathrm{~b}$ \\
\hline 10 & --- & $3.7 \mathrm{a}$ & $\cdots$ & $1.0 \mathrm{c}$ \\
\hline Control $\bar{X}$ & 4.9 & 4.3 & 0.0 & 0.3 \\
\hline Stressed $\bar{Y}$ & 4.8 & 3.2 & 0.3 & 1.4 \\
\hline \multicolumn{5}{|l|}{ Contrasts } \\
\hline Control vs. cold & NS & $* *$ & $*$ & $* *$ \\
\hline \multicolumn{5}{|l|}{$\begin{array}{l}\text { Sources of } \\
\text { variation }\end{array}$} \\
\hline Replication & 1 & $7^{*}$ & 1 & 7 \\
\hline Duration (D) & $50^{* *}$ & $35^{* *}$ & $49 * *$ & $28 * *$ \\
\hline Frequency $(\mathrm{F})$ & $16^{* *}$ & $27^{* *}$ & $22^{* *}$ & $35^{* *}$ \\
\hline $\mathrm{D} \times \mathrm{F}$ & $15^{* *}$ & $13^{* *}$ & $15^{* *}$ & $11^{* *}$ \\
\hline Error & 19 & 18 & 13 & 19 \\
\hline
\end{tabular}

${ }^{z}$ Means within column and main effects separated by least significant difference at $P=0.05$.

${ }^{y}$ Composed of only those sources of variation given in this ANOVA. Ns, *,**Nonsignificant or significant at $P=0.05$ or 0.10 , respectively. to $12 \mathrm{hr}$ increased the number of dead leaves and reduced the number of live leaves. In the second experiment, as duration increased from 6 to $18 \mathrm{hr}$, incidence of transplant shock increased.

As cold-stress frequency increased from 1 to 6 days in the first experiment and from 4 to 10 days in the second experiment, the incidence of transplant shock increased progressively (Table 4). Although of lesser importance, the interaction between duration and frequency was significant in both experiments. Since the behavior was similar in both years, only the data from the second experiment are presented in Table 5. Transplant shock was similar in plants exposed repeatedly to cold stress lasting from 6 to $18 \mathrm{hr}$ for 4 days. In contrast, increasing stress duration from 6 to $18 \mathrm{hr}$ repeatedly for 7 to 10 days increased transplant shock.

Although transplant growth and development and incidence of transplant shock were affected by cold-stress treatments, longterm detrimental or beneficial effects on earliness were not evident. Earliness to flower and fruit was unaffected by cold-stress duration in both experiments (data not shown). About 25 and 29 days were required for seedlings to flower in the first and second experiments, respectively. Days to first fruit was not recorded in the first experiment, but in the second experiment, the first fruit on the first fruit cluster required 52 days to be easily visible.

Marketable yield over the entire harvest season was unaffected by cold-stress treatment (Table 6). There was a trend for total production to be higher for cold-stressed than for non-coldstressed plants in the second experiment, but not the first. Size distribution, fruit quality, and incidence of blemishes were not affected by cold-stress duration.

\section{Discussion}

Differential cold-stress durations and frequencies were found to be generally stimulator to seedling growth and development in the first experiment. The longer periods of cold stress may have arrested seedling respiration in contrast to those seedlings placed for longer periods in the greenhouse. Since temperature influences respiration, longer periods of high temperatures in the light may have increased substrate respiration. However, extremes of cold stress in the second experiment deterred growth. Extended periods of cold may have permanently injured photosynthetic apparatus, as indicated by reduced chlorophyll content. Several studies have documented that chilling sensitivity of tomato seedlings is moderated by high carbohydrate levels (King et al., 1988), by light/dark cycles (King and Reid, 1987), and by short-term cold acclimation (Shen and Li, 1983).

Attempts to control the illumination of seedlings during cold stress by using the coolers as a phytotron were not successful. It was not possible to cool the illuminated coolers to the desired

Table 5. Interaction of low-temperature stress duration and frequency on the presence of chlorotic leaves 11 days after field transplanting.

\begin{tabular}{|c|c|c|c|c|}
\hline \multirow{3}{*}{$\begin{array}{l}\text { Duration } \\
\text { (hr) }\end{array}$} & \multicolumn{4}{|c|}{ No. of chlorotic leaves/plant } \\
\hline & \multicolumn{4}{|c|}{ Frequency (days) ${ }^{z}$} \\
\hline & 0 & 4 & 7 & 10 \\
\hline 0 & $4.0 \mathrm{a}$ & $\cdots$ & --- & -- \\
\hline 6 & --- & $1.6 \mathrm{bcd}$ & $0.6 \mathrm{e}$ & $0.8 \mathrm{e}$ \\
\hline 12 & -- & $1.7 \mathrm{bcd}$ & $1.4 \mathrm{~cd}$ & $0.7 \mathrm{e}$ \\
\hline 18 & --- & $2.0 \mathrm{~b}$ & $1.9 \mathrm{bc}$ & $1.3 \mathrm{~d}$ \\
\hline
\end{tabular}

${ }^{2}$ Mean separation within rows and columns by least significant difference test at $P=0.05$. 
Table 6. Effects of low-temperature stress duration and frequency on tomato yield in 1987 and 1988.

\begin{tabular}{|c|c|c|}
\hline \multirow[b]{2}{*}{ Cold stress } & \multicolumn{2}{|c|}{$\begin{array}{c}\text { Marketable yield } \\
\left(\mathrm{t} \cdot \mathrm{ha}^{-1}\right)^{\mathrm{z}}\end{array}$} \\
\hline & 1987 & 1988 \\
\hline \multicolumn{3}{|l|}{ Duration (hrs) } \\
\hline 3 & $41.2 \mathrm{a}^{z}$ & $\cdots$ \\
\hline 6 & $40.0 \mathrm{a}$ & $49.5 \mathrm{a}$ \\
\hline 12 & $44.0 \mathrm{a}$ & $51.4 \mathrm{a}$ \\
\hline 18 & --- & $50.3 \mathrm{a}$ \\
\hline \multicolumn{3}{|l|}{ Frequency (days) } \\
\hline 1 & $38.8 \mathrm{a}$ & -- \\
\hline 3 & $45.6 \mathrm{a}$ & -.- \\
\hline 4 & -- & $52.4 \mathrm{a}$ \\
\hline 6 & $40.4 \mathrm{a}$ & $\cdots$ \\
\hline 7 & --- & $52.3 \mathrm{a}$ \\
\hline 10 & -.. & $53.0 \mathrm{a}$ \\
\hline Control $\bar{X}$ & 44.6 & 41.2 \\
\hline Stressed $\overline{\mathrm{X}}$ & 41.5 & 51.5 \\
\hline \multicolumn{3}{|l|}{ Contrasts } \\
\hline Control vs. cold & NS & $*$ \\
\hline \multicolumn{3}{|l|}{$\begin{array}{l}\text { Sources of } \\
\text { variation }\end{array}$} \\
\hline Replication & 5 & 19 \\
\hline Duration (D) & 4 & 0 \\
\hline Frequency (F) & 15 & 6 \\
\hline $\mathrm{D} \times \mathrm{F}$ & 19 & 9 \\
\hline Error & 57 & 66 \\
\hline
\end{tabular}

${ }^{2}$ Means within columns and main effects separated by least significant difference at $P=0.05$.

${ }^{y}$ Composed of only those sources of variation given in this ANOVA. NS, *Nonsignificant or significant at $P=0.05$, respectively.

$2 \mathrm{C}$, since heat from the light units increased the temperature of the cooler to a minimum of $4.4 \mathrm{C}$. Hence, cold-stress imposition was planned to occur in darkness, commencing as early as late afternoon and throughout the evening and early morning hours to reduce the number of hours of light deprivation. Therefore, it is unknown what effect the increased periods of darkness imposed during cold stress had on seedling growth.

We found that, although short-term cold stresses affected gross seedling growth and appearance, these aberrations were not detrimental to the yielding capacity of 'Sunny' tomatoes. There were no long-term effects to short-term cold stresses that occurred before transplanting; thus, 'Sunny' can be considered. relatively cold tolerant during this developmental period. In the first experiment, the stress levels evaluated were chosen to approximate those potential stresses common in the field in coastal
South Carolina. Since tomato earliness, yield, and quality were unaffected, more-rigorous cold stress regimes were used in the second experiment with cumulative cold stresses ranging from as short as $24 \mathrm{hr}$ at $2 \mathrm{C}$ to as much as $180 \mathrm{hr}$. Even though these regimes were unrealistic, the second experiment confirmed that cold stresses occurring during transplant hardening of 'Sunny' tomato were not detrimental, but may be considered an enhancement of total productivity. The marketable yield of all cold-stress treatments pooled compared to that of the non-coldstressed treatment indicated a higher yield for the former. This study implies that transplanting the cultivar Sunny into the field may occur under very cool field conditions and will not likely cause significant reductions in yield potential.

\section{Literature Cited}

Brasher, E.P. 1941. Growth and yield of the tomato plant when hardened with certain nutrient solutions. Proc. Amer. Soc. Hort. Sci. 38:629-632.

Brasher, E.P. and K.C. Westover. 1937. The effect on yield of hardening the tomato plant. Proc. Amer. Soc. Hort. Sci. 35:686-689.

Christiansen, N. and R. Thomas. 1969. Season-long effects of chilling treatments applied to germinating cottonseed. Crop Sci. 9:672-673.

Currah, I. 1978. Plant uniformity at harvest related to variation between emerging seedlings. Acta Hort. 72:57-69.

Hegarty, T. and R. Thompson. 1974. Red beet: production and processing. Ann. Rept. Scottish Res. Inst. 1973:26-27.

Henriksen, K. 1978. Sowing depth and N-fertilizing in relation to yield and uniformity in onion crops. Acta Hort. 72:69-75.

King, A., D. Joyce, and M. Reid. 1988. Role of carbohydrates in diurnal chilling sensitivity of tomato seedlings. Plant Physiol. 86:764768.

King, A. and M. Reid. 1987. Diurnal chilling sensitivity and desiccation in seedlings of tomato. J. Amer. Soc. Hort. Sci. 112:821824.

Moran, R. 1982. Formulae for determination of chlorophyllous pigments extracted with N, N-dimethylformamide. Plant Physiol. 69:13761381.

Porter, A.M. 1936. Retarding effect of hardening on yield and earliness of tomatoes. Proc. Amer. Soc. Hort. Sci. 33:542-544.

Shen, Z. and P.H. Li. 1983. Induction of frost hardiness in tomato leaves by short-term cold acclimation. HortScience 18:730-732.

Wheaton, T. and L.L. Morris. 1968. Modification of chilling sensitivity by temperature conditioning . Proc. Amer. Soc. Hort. Sci. 91 :529 533.

Wittwer, S.H. and F.G. Teubner. 1956. New practices for increasing the fruit crop of greenhouse-grown tomatoes. Mich. Agr. Expt. Sta. Quart. Bul. 39:198-207.

Wittwer, S.H. and F.G. Teubner. 1957. The effects of temperature and nitrogen nutrition on flower formation in the tomato. Amer. J. Bot. 44:125-129. 